\title{
Importance and Challenges of Electrochemical in Situ Liquid Cell Electron Microscopy for Energy Conversion Research
}

\author{
Published as part of the Accounts of Chemical Research special issue "Nanoelectrochemistry".
}

Nejc Hodnik, $*, \dagger, \ddagger$ Gerhard Dehm, ${ }^{\dagger}$ and Karl J. J. Mayrhofer ${ }^{\dagger, \S, \|}$

${ }^{\dagger}$ Max-Planck-Institut für Eisenforschung GmbH, Max-Planck-Strasse 1, 40237 Düsseldorf, Germany

${ }^{\ddagger}$ Department of Catalysis and Chemical Reaction Engineering, National Institute of Chemistry, Hajdrihova 19, 1000 Ljubljana, Slovenia

${ }^{\S}$ Helmholtz-Institute Erlangen-Nürnberg for Renewable Energy (IEK-11), Forschungszentrum Jülich, Egerlandstr. 3, 91058 Erlangen, Germany

"Department of Chemical and Biological Engineering, Friedrich-Alexander-Universität Erlangen-Nürnberg, Egerlandstr. 3, 91058 Erlangen, Germany

\section{Supporting Information}

CONSPECTUS: The foreseeable worldwide energy and environmental challenges demand renewable alternative sources, energy conversion, and storage technologies. Therefore, electrochemical energy conversion devices like fuel cells, electrolyzes, and supercapacitors along with photoelectrochemical devices and batteries have high potential to become increasingly important in the near future. Catalytic performance in electrochemical energy conversion results from the tailored properties of complex nanometer-sized metal and metal oxide particles, as well as support nanostructures. Exposed facets, surface defects, and other structural and

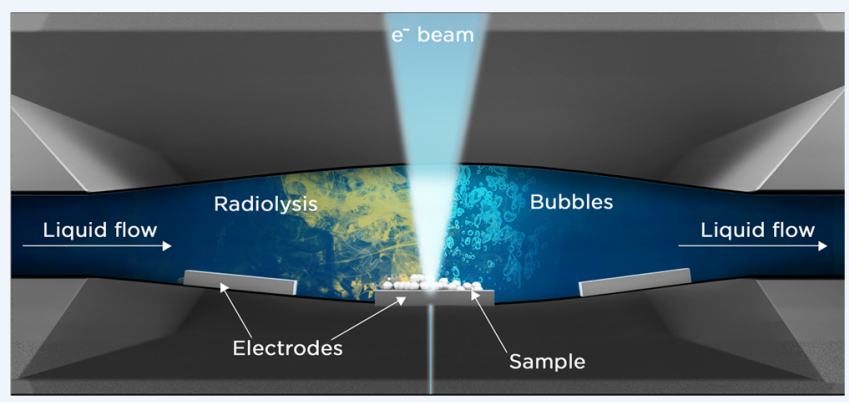
compositional features of the catalyst nanoparticles affect the electrocatalytic performance to varying degrees. The characterization of the nanometer-size and atomic regime of electrocatalysts and its evolution over time are therefore paramount for an improved understanding and significant optimization of such important technologies like electrolyzers or fuel cells. Transmission electron microscopy (TEM) and scanning transmission electron microscope (STEM) are to a great extent nondestructive characterization tools that provide structural, morphological, and compositional information with nanoscale or even atomic resolution. Due to recent marked advancement in electron microscopy equipment such as aberration corrections and monochromators, such insightful information is now accessible in many institutions around the world and provides huge benefit to everyone using electron microscopy characterization in general.

Classical ex situ TEM characterization of random catalyst locations however suffers from two limitations regarding catalysis. First, the necessary low operation pressures in the range of $10^{-6}$ to $10^{-9} \mathrm{mbar}$ for TEM are not in line with typical reaction conditions, especially considering electrocatalytic solid-liquid interfaces, so that the active state cannot be assessed. Second, and somewhat related, is the lack of time resolution for the evaluation of alterations of the usually highly heterogeneous nanomaterials. Two methods offer a solution to these shortcomings, namely, identical location TEM (IL-TEM) and electrochemical in situ liquid TEM. The former is already well established and has delivered novel insights particularly into degradation processes; however, characterization is still performed in vacuum. The latter circumvents this issue by using dedicated in situ TEM holders but introduces extremely demanding technical challenges. Although the introduction of revolutionizing thin $\mathrm{SiN}$ window cells, which elegantly confine the specimen from vacuum, has allowed demonstration of the potential of the in situ approach, the reproducibility and data interpretation is still limited predominately due to the strong interaction of the electron beam with the supporting electrolyte and electrode material. Because of the importance of understanding the nanoelectrochemical structurefunction relationship, this Account aims to convey a timely perspective on the opportunities and particularly the challenges in electrochemical identical location TEM and in situ liquid cell TEM with a focus on electrochemical energy conversion.

\section{INTRODUCTION}

All electrochemical devices have in common that they are based on complex electronically conducting nanostructures, often consisting of active metal and metal oxide particles finely dispersed on a support material. ${ }^{1}$ In order to deepen knowledge of time- and potential-resolved changes, for example, degradation processes, nanoscale electrochemistry character-

Received: June 30, 2016

Published: August 19, 2016 
Scheme 1. Degradation Mechanisms for Nanoparticles on a Model Support ${ }^{a}$

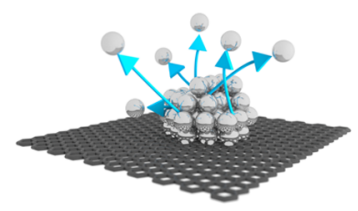

Platinum Dissolution

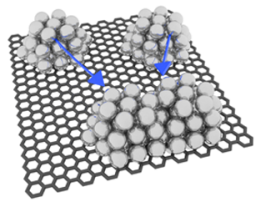

Agglomeration

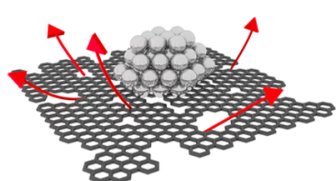

Carbon Corrosion

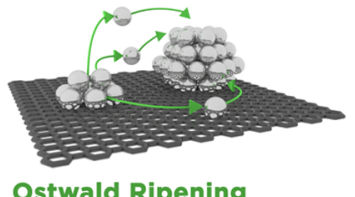

Ostwald Ripening

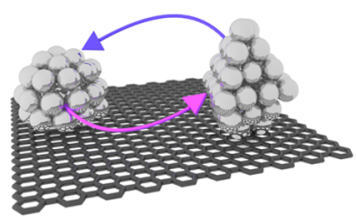

Reshaping

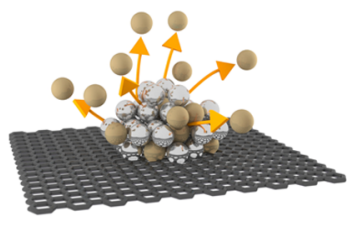

Dealloying

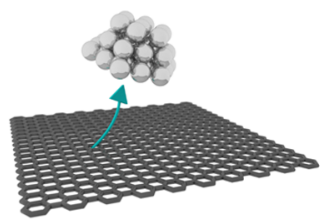

Particle Detachment

${ }^{a_{\text {The }}}$ most representative for PEM-FC would be a Pt-alloy on a carbon support.

ization techniques need to be explored and developed further. ${ }^{2}$ Although spectroscopic techniques, like X-ray absorption spectroscopy (XAS), Raman, infrared (IR), sum frequency generation (SFG), etc., provide invaluable information about the surface species at the atomic or molecular level, they do not offer lateral structural resolution. Surface sensitive techniques, like AFM, STM, etc., are potential candidates for nanoscale analysis of the topmost atomic layers of model surfaces; however, they cannot be applied on heterogeneous micro- and nanostructured surfaces. ${ }^{3,4}$ Therefore, in principle, only TEM/ STEM, with its variety of signals ranging from atomic resolution $Z$-contrast imaging ( $Z=$ atomic number) using a high-angle annular dark-field detector (HAADF), electron energy loss spectroscopy (EELS), or energy-dispersive X-ray spectroscopy (EDS or EDX) to various electron diffraction (ED) techniques, is able to provide the essential nanoscale resolved spatial and spectroscopic information on surface and near surface area of high-surface area nanostructures. Nevertheless, all the above-mentioned techniques perfectly complement each other and together with computational studies contribute to a complete physical picture of the electrochemical interfaces. $^{5}$

The first TEM was constructed by Ernst Ruska and Max Knoll already in 1931. Two years later, in 1933, Ruska built an electron microscope that exceeded the resolution achievable by an optical microscope for which he received the Nobel Prize. Since then TEM advanced significantly, and atomic resolution nowadays has become a common feature in many studies. Structural analysis of materials on a nanoscale under realistic or close to realistic conditions and under different external stimuli, also referred as in situ or sometimes operando, was recognized already in 1942, again by Ruska. ${ }^{6}$ Although slow progress followed its invention, it has received great interest of researchers across many scientific fields in the last two decades. $^{7}$ This is mostly due to the significant advancement in aberration correction and monochromators. ${ }^{8}$ In situ TEM is now a fast growing area of research with numerous possibilities to study samples under applied heat, stress, light excitation, magnetic or electric fields, and also electrochemical control. $3,4,7,9-16$ Among the different types of specimen holders that offer control over sample environment, two basic concepts are used, namely (gas) environmental and thin-windowed cell TEM holder. The first one is based on a differential pumped microscope, in which the specimen is placed without any physical separation ("open cell" approach) from the vacuum and is locally exposed to a low pressure of the gas of interest (environmental TEM). The key issue is to find an optimal balance between as high as possible confined gas pressure in the close vicinity of the specimen, while still maintaining high microscope performance. ${ }^{17}$ Gas pressures in ETEM experiments generally range from $10^{-5}$ mbar up to 20 mbar (typical limit in the case of nitrogen gas); higher pressures are not acceptable for the technical components of the TEM. The second configuration is not limited by the low pressure environment, since the specimen is physically separated from the vacuum. This is achieved by the use of a so-called thinwindow cell that consists of two electron beam transparent membranes (usually $\mathrm{SiN}_{x}$ ) on a silicon support enclosing the observed specimen and its liquid or gaseous environment. It had been developed already in the year 1962 by Heide, ${ }^{18}$ however only recently greater resolutions became available by thinning of the thin-window cell to $\leq 50 \mathrm{~nm} .{ }^{19}$ Through this technology new insights into the behavior of materials in liquids are being realized. In particular, a great opportunity can be recognized to study electrochemical phenomena at the solidliquid interface in situ. In this Account, we present specific capabilities, challenges, and limitations of identical location and electrochemical in situ liquid TEM, by focusing on a wellstudied example in low-temperature electrochemical energy conversion, namely, the stability of platinum based electrocatalyst nanoparticles. $^{20}$

\section{LOW-TEMPERATURE FUEL CELL PERFORMANCE AND DURABILITY}

Although the properties and performance of the electrodes of polymer exchange membrane fuel cells (PEM-FC) have been 
extensively studied in the last decades, ${ }^{1,20}$ still several aspects are not completely resolved. ${ }^{21}$ Exposed facets, surface defects, the nature of the surface oxide, the near surface composition of the metal nanoparticles, and support interactions all govern its electrochemical properties. ${ }^{22-27}$ The formation of different platinum based nanoparticle morphologies (specific shapes, $^{22,24,28}$ skeleton or skin, ${ }^{25}$ porous or core-shell ${ }^{29,30}$ nanoparticle configurations), as well as the resulting oxygen reduction reaction performance depends on particle composition, ${ }^{23,26,30,31}$ nature of defects, ${ }^{27}$ size, ${ }^{28,31,32}$ structural ordering, $^{26,33}$ and also dealloying conditions. ${ }^{26,29}$ It seems that the activity of these materials is already adequate, since many recent reports already fulfill international targets for acceptable metal loading. ${ }^{20,34-36}$ However, sustaining those activities for all the suggested materials in the long run remains an open challenge. In numerous simulated PEM-FC stability studies, ${ }^{31,37-41}$ it has been shown that the main degradation mechanisms are $\mathrm{Pt}$ dissolution and carbon corrosion, as well as leaching or dealloying for promising Pt-alloys (Scheme 1). ${ }^{28,30-32,39,40,42}$ Also secondary mechanisms as a consequence of the above were identified, like Ostwald ripening, platinum segregation, particle detachment, atomic rearrangement or reshaping, coalescence, or agglomeration..$^{21,28,37,38,40-46}$ Due to high lateral resolution, strong $Z$-contrast, and its nondestructive nature, electron microscopy has been utilized to study localized morphological changes of $\mathrm{Pt}$ or other heavy metal element based nanoparticles. ${ }^{4,47}$

\section{IDENTICAL LOCATION TEM (EX SITU)}

IL-TEM was introduced in 2008 for the tracking of morphological surface changes on the nanoscale, by investigating identical locations of electrocatalyst materials before and after electrochemical aging. ${ }^{43}$ Compared with usual imaging of random locations of material with certain statistical uncertainty, it provides direct insight into the studied events. ${ }^{21,41}$ Thus, sound conclusions on complex degradation phenomena of nanoparticulate catalysts under various reaction conditions could be drawn. ${ }^{21,41}$ IL-TEM is now well established in the PEM-FC community for degradation studies including various types of electrocatalysts and different potential/current protocols. $^{21,26,41,48-53}$ The whole TEM toolbox ${ }^{21}$ with ILHAADF-STEM, $^{54}$ IL-EELS $^{54}$ (Figure 1), IL-tomography, ${ }^{21,26}$ or even IL-SEM can be applied to obtain complementary information on the surface topology and composition of the specimen. $^{21,42,46,55}$ Identical location is a straightforward and affordable method and has been recognized as a useful approach to study any morphological and structural changes of electron microscopy compatible samples, not only Pt-based materials. $^{55-58}$ While it does not provide true in situ information and suffers from time-consuming sample transfer, the approach has the advantage that both electrochemical analysis and electron microscopy can be basically utilized without constraints.

\section{IN SITU LIQUID CELL TEM}

The ultimate goal of in situ liquid cell TEM, a natural extension of IL-TEM, is to be able to visually follow and record timeresolved processes at the nanoscale, with full capabilities despite a liquid media. For that purpose, the micro-electromechanical systems (MEMS) based thin-windowed cells seem to offer the solution. ${ }^{59}$ Silicon nitride membranes are strong enough to protect the vacuum from the liquid and thin enough $(\sim 50 \mathrm{~nm})$
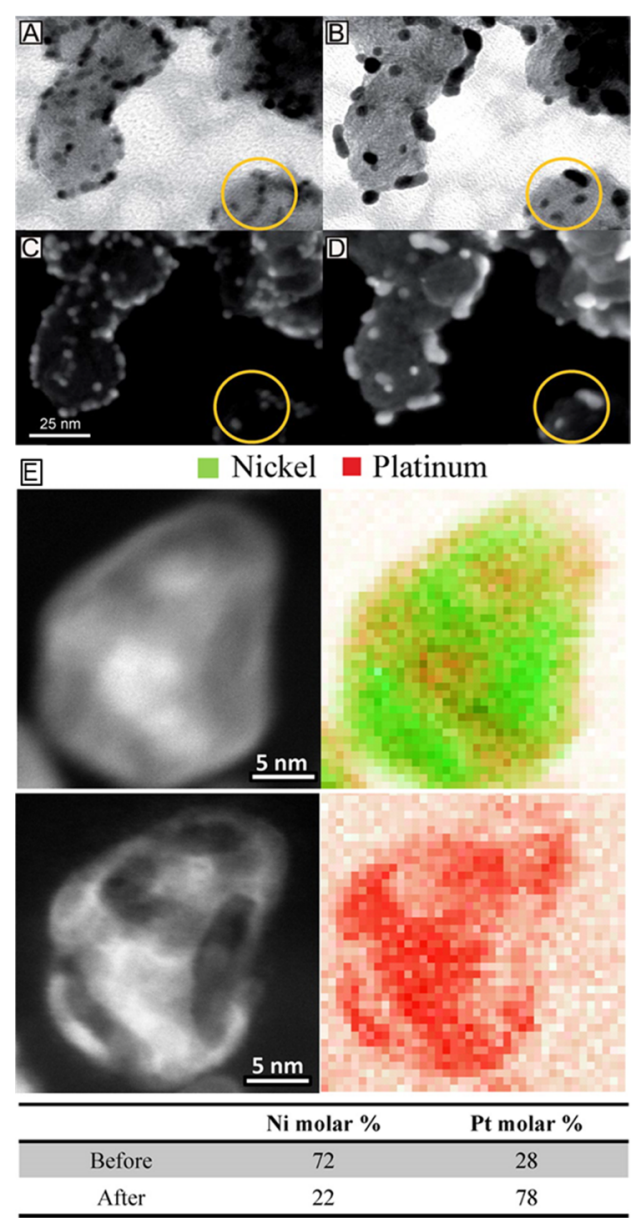

Figure 1. (A, B) Bright-field-STEM and (C, D) SEM images of an identical catalyst location of a Pt/C catalyst $(3.6 \mathrm{~nm}, 20 \mathrm{wt} \% \mathrm{Pt}$, VulcanXC72R) before (A, C) and after (B, D) 3600 degradation cycles (0.4-1.4 VRHE, $\left.1 \mathrm{~V} \mathrm{~s}^{-1}\right)$. Reproduced with permission from ref 21. Copyright 2012 Royal Society of Chemistry. (E) HAADF micrographs (left column) and corresponding element distribution images using electron spectroscopy imaging (ESI, right column) of a single representative nanoparticle before (upper row) and after (bottom row) activation (i.e., 200 cycles between 0.05 and 1.2 VRHE at $0.5 \mathrm{~V} \mathrm{~s}^{-1}$ ). Quantitative results of the overall compositional analysis on the nanoparticle (bottom table). Adapted with permission from ref 54. Copyright 2015 American Chemical Society.

to be transparent for the electron beam. ${ }^{19}$ The basic proof of concept of liquid in situ TEM has recently been shown with different homemade thin-windowed ${ }^{19,59-62}$ and commercial cells (e.g., Protochips, Hummingbird or DENSsolutions). Insightful overviews on the developments have been summarized by N. de Jonge and F.M. Ross, two pioneers in this field. ${ }^{19,60}$

Through the advancement of thin-film and MEMS technology, it is now possible to visually study various exciting topics ranging from life to material science. ${ }^{19,60}$ The issue of electron beam induced damage is the biggest experimental limitation of in situ liquid microscopy. This is why most liquid in situ EM applications took advantage of this practically unavoidable effect to initially study and report beam induced nanoparticle nucleation, growth, dissolution, coalescence, motion, colloid aggregation, self-assembly, bubble formation, etc. $^{19,60,62-72}$ Impressive resolutions (Figure 2) were achieved by use of aberration correction, high-speed imaging ${ }^{64}$ and 


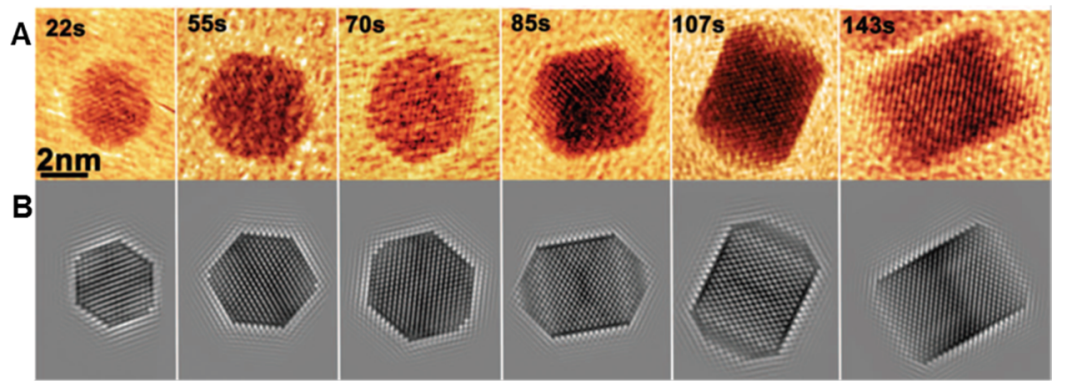

Figure 2. Facet development of a Pt nanocube viewed along the [011] axis in $50 \mathrm{~mL}$ of Pt(acetylacetonate) ${ }_{2}$ in a solvent mixture of oleylamine, oleic acid, and pentadecane (4.5:1.5:4). (A) Sequential images demonstrate the growth of a Pt nanocube. (B) Simulated TEM images of the Pt nanoparticle in part A. Reproduced with permission from ref 64. Copyright 2014 American Association for the Advancement of Science.

graphene windows. ${ }^{65}$ In combination with local elemental and chemical analysis $\left(\mathrm{EDS}^{73}\right.$ and $\mathrm{EELS}^{74}$ ) in situ liquid cell TEM has evolved to a powerful tool. Further optimizations of the resolution are possible in thinning of the electron beam path by (i) thinning the liquid layer, (ii) by thinning the $\mathrm{SiN}_{x}$ membranes, or (iii) by enabling easy use of advanced materials like graphene.

One particular challenge has been realized in studies with water based electrolytes, in which products of water radiolysis are formed as a result of high energy electron interaction with water molecules. The excitation leads to the formation of many different species, including hydrated (solvated) electrons $\left(\mathrm{e}_{\mathrm{h}}{ }^{-}\right)$, hydrogen and hydroxyl radicals, hydrogen, peroxide, hydronium ions, etc. These species are a function of electron dose rate and can alter the measurements by changing the $\mathrm{pH}$, oxidation/reduction environment, bubble formation, colloid aggregation, etc. ${ }^{66,70}$ In order to reduce the effect for instance, scavenger species can be introduced that react with solvated electrons. ${ }^{75}$ Alternatively, the electron beam dose can be reduced at the expense of using signal processing like compressive sensing to retrieve the missing information. ${ }^{76}$

\section{ELECTROCHEMICAL IN SITU LIQUID CELL TEM}

Compared with liquid cell TEM, many fewer reports have been published on the topic of in situ electrochemistry, although one of the first experiments performed in modern MEMS thinwindowed type cell has been the electrochemical deposition of copper. ${ }^{77}$ Electrochemical control over reactions has been recognized early on to be important, because it offers a direct measure of the rate. With the increase in availability of MEMS production with precise control concerning the thickness of the $\mathrm{SiN}_{x}$ membrane windows, as well as implementation of channels to confine liquids and electrodes, electrochemical in situ liquid cell TEM is gaining popularity for topics like metal deposition, ${ }^{77-80}$ corrosion, ${ }^{81}$ fuel cells, ${ }^{82-84}$ and batteries,. ${ }^{74,85-89}$

Recent significant works on the topic of solution-phase nanoparticle growth with impressive atomic resolutions ${ }^{64,65,72}$ (Figure 2) and chemical analysis ${ }^{73,74}$ exemplifies the capabilities of electrochemical in situ liquid cell TEM. The current state-ofthe-art resolution in water based medium is in the range of a few nanometers (more often $10 \mathrm{~nm}$ ), which holds potential for improvement. ${ }^{74,77-88,90,91}$ Advances are also needed in controlling of electrochemical potential, quantification of the electrochemical signal under the electron beam, electrode configuration, and size. A precondition for imaging in liquid is to keep the electron dose rate below the threshold for its decomposition. ${ }^{66}$ If bubble formation cannot be avoided, the option of a flow cell is beneficial, since it enables removal of the irradiation products faster compared with the stagnant cell.

Holtz et al. ${ }^{74}$ and Unocic et al. ${ }^{92}$ used platinum electrodes to show that electrochemical measurements can be qualitative and quantitative. Negligible effect of irradiation on electrochemical measurement between beam on and beam off was demonstrated. The beam dose rate used in the two mentioned studies, which is a function of magnification, the size of exposed illuminated area of an electrode, and "electron adsorptive ability" of an electrode material, was in the range of 100-500 $\mathrm{e}^{-} /\left(\mathrm{nm}^{2} \mathrm{~s}\right) .^{74,92}$ If we consider currents in a range of $10 \mathrm{nA}$ on a $100 \times 20 \mu \mathrm{m}^{2}$ electrode, this current density translates to an electron dose of 31 electrons per $\mathrm{nm}^{2}$. Therefore, if the size of electrode is small and the beam dose large, it is reasonable to expect alterations of the measured electrochemical signal. The electron dose can indeed be observed as superimposed signal (STEM mode) over the typical platinum cyclic voltammogram (CV) (Figure S1). As the shutter is opened, the scanning rate of the electron beam directly correlates with the spike pattern in the CV. In addition, also the whole CV elevates and begins to shift due to electrolyte decomposition (radiolysis). Further efforts are required to better understand and control these phenomena and their consequences, to finally reduce any crossinterferences of electrochemical and TEM induced signals.

Besides water radiolysis, irradiation can cause also a lowering of the electrochemical potential through absorption in the specimen. If one studies $\mathrm{Pt}$ based nanocatalyst degradation induced by potential cycling, similar to the ones studied with IL-TEM, the dominant mechanisms are usually agglomeration and dissolution. In contrast, we (Figure 3) and a few other groups observed unrealistic growth of $\mathrm{Pt}$ particles, ${ }^{82,83}$ suggesting that Pt deposition takes place. Pt deposition starts
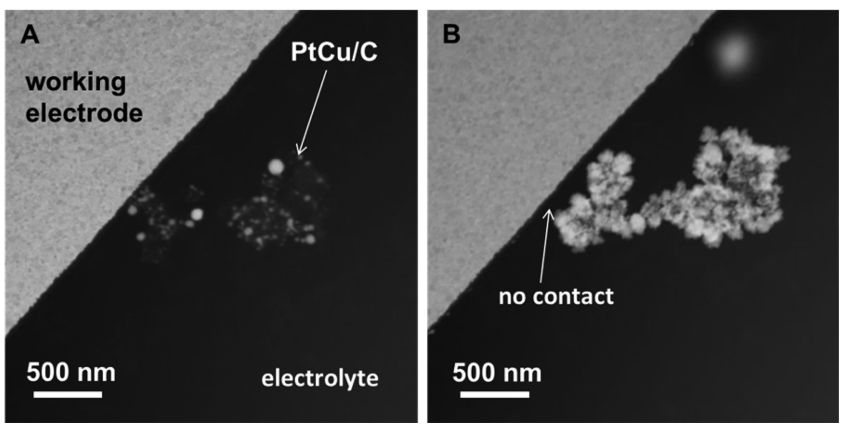

Figure 3. Electrochemical in situ liquid cell TEM micrograph of $\mathrm{PtCu} /$ C electrocatalysts before (A) and after (B) 150 potential cycles $0.5 \mathrm{~V} / \mathrm{s}$ in $0.1 \mathrm{M} \mathrm{HClO}_{4}$. 
when the $\mathrm{PtCu} / \mathrm{C}$ aggregate loses potential control due to detachment from the working electrode and is thereafter accelerated by the negative charging under the electron beam (Movie S1). Note that no deposits were observed at neighboring locations that were still in contact with the electrode. The source of $\mathrm{Pt}$ for deposition stems from $\mathrm{Pt}$ dissolution at other locations on the electrode (including also counter and reference electrodes made out of $\mathrm{Pt}$ ) upon cycling. ${ }^{93}$ Further experimental results can be found in the Supporting Information.

Another issue is the control over the electrochemical potential of the specimen. The uniformity of the electric field distribution along the working electrode (WE) is influenced by the position of the counter electrode (CE). Usually two types of electrode configurations are found in literature, either linear ${ }^{87}$ or concentric. ${ }^{82,85}$ Nonuniformity of the electric field gradient can cause localized "hot spots" where, for instance, the deposition rate increases. ${ }^{87}$ The electrochemical potential of the WE is controlled by the ability of the reference electrode (RE) to hold a constant potential and the CE to supply current without altering the electrolyte composition by water splitting creating oxygen and hydrogen. In most electrochemical in situ studies, Pt was used as the RE and CE due to practical reasons. It possesses high corrosion stability and metallic conductivity, and it is already used in the fabrication processes of state-of-theart MEMS thin-windowed cells. However, Pt is known to be highly sensitive toward changes in electrolyte composition, like the presence of oxygen or hydrogen or change in $\mathrm{pH}$, and it is also known to dissolve, ${ }^{93}$ so that new RE materials should be explored. Palladium, which can be saturated with hydrogen, could act as an ideal reversible hydrogen electrode (RHE), while iridium or simply carbon would be favorable as CE due to high corrosion resistance and lower interference. ${ }^{93}$ Alternatively, classical $\mathrm{Ag} / \mathrm{AgCl} \mathrm{RE}$ could be used; however, to avoid chloride contamination of the sample, the $\mathrm{Ag} / \mathrm{AgCl} \mathrm{RE}$ must be isolated.

\section{CONCLUSIONS}

Recent advances in nanoscale observation of materials and material processes by TEM/STEM are tremendous. We are now able to observe the atomistic structure and chemistry not only in vacuum but also in liquid environments. Several challenges of electrochemical in situ liquid cell TEM must however be mastered to provide detailed operando insights into the catalytic mechanisms. Currently, one of the biggest limitations is electron beam irradiation, because it alters the chemistry of the suspending liquid environment and interferes with the electrochemical signal. Reducing the electron beam dose can circumvent these limitations but requires countermeasures to compensate for the loss in image quality. Improved camera systems with higher detection efficiency or the use of compressive sensing software are potential solutions. Lowering the radiolysis of water, further optimization over the nanoelectrochemical cell, and proper electrode preparation will pave the way to exciting electrochemical in situ liquid electron microscopy and its widespread application for the characterization of new materials in the field of electrochemical energy conversion.

\section{ASSOCIATED CONTENT}

\section{Supporting Information}

The Supporting Information is available free of charge on the ACS Publications website at DOI: 10.1021/acs.accounts.6b00330.

Movie of images from Figure 3 (AVI)

Movie of images from Figure S2 (AVI)

Movie of images from Figure S3 (AVI)

In situ liquid cell electron microscopy movie of behavior of $\mathrm{PtCu}$ electrocatalysts nanoparticles attached to $\mathrm{SiN}_{x}$ membrane in $0.1 \mathrm{M} \mathrm{HClO}_{4}$ electrolyte (AVI)

Description of IL-SEM, Pt cyclic voltammograms, electrochemical in situ liquid cell TEM micrographs, and descriptions of movies (PDF)

\section{AUTHOR INFORMATION}

\section{Corresponding Author}

*E-mail: nejc.hodnik@ki.si.

Notes

The authors declare no competing financial interest.

\section{Biographies}

Nejc Hodnik completed his Ph.D. in 2013 at the National Institute of Chemistry (NI). Afterwards, he has been working as a Marie Curie Intra-European fellow associated with the groups of Prof. Mayrhofer and Prof. Dehm at the MPIE. In 2016, he became staff researcher in the field of electrochemical energy conversion at NI.

Gerhard Dehm obtained his Ph.D. in 1995 at the Max-PlanckInstitute for Metals Research in Stuttgart. He later spent two years at the Technion (Israel Institute of Technology) supported by an Alexander von Humboldt scholarship. In 1999, he returned to the MPI for Metals Research as a group leader. In 2005, he became Professor of Material Physics and Head of the Department Materials Physics at the Montanuniversität Leoben, Director of the Erich Schmid Institute for Material Science of the Austrian Academy of Sciences. Since 2012, he is Director at the MPIE and Professor at the Ruhr-Universität Bochum.

Karl Mayrhofer received his Ph.D. from the TU Vienna in 2006 after a research stay at the Lawrence Berkeley National Lab with Dr. N. Markovic. He then spent three years with Prof. M. Arenz at the TU München before becoming a group leader at the MPIE. In 2015, he was appointed Professor for Electrocatalysis at the Friedrich-Alexander Universität Erlangen-Nürnberg and Director of the Helmholtz-Institut Erlangen-Nürnberg of the Forschungszentrum Jülich.

\section{ACKNOWLEDGMENTS}

This research was supported by a Marie Curie Intra European Fellowship within the 7th European Community Framework Programme and by the Max-Planck-Society.

\section{REFERENCES}

(1) Katsounaros, I.; Cherevko, S.; Zeradjanin, A. R.; Mayrhofer, K. J. J. Oxygen Electrochemistry as a Cornerstone for Sustainable Energy Conversion. Angew. Chem., Int. Ed. 2014, 53, 102-121.

(2) Oja, S. M.; Fan, Y.; Armstrong, C. M.; Defnet, P.; Zhang, B. Nanoscale Electrochemistry Revisited. Anal. Chem. 2016, 88, 414430.

(3) Tao, F.; Crozier, P. A. Atomic-Scale Observations of Catalyst Structures under Reaction Conditions and during Catalysis. Chem. Rev. 2016, 116, 3487-3539. 
(4) Su, D. S.; Zhang, B.; Schlögl, R. Electron Microscopy of Solid Catalysts-Transforming from a Challenge to a Toolbox. Chem. Rev. 2015, 115, 2818-2882.

(5) Greeley, J.; Markovic, N. M. The road from animal electricity to green energy: combining experiment and theory in electrocatalysis. Energy Environ. Sci. 2012, 5, 9246-9256.

(6) Ruska, E. Beitrag zur übermikroskopischen Abbildung bei höheren Drucken. Colloid Polym. Sci. 1942, 100, 212-219.

(7) Dehm, G.; Howe, J. M.; Zweck, J. In-situ Electron Microscopy: Applications in Physics, Chemistry and Materials Science; Wiley-VCH Verlag GmbH \& Co. KGaA: Weinheim, Germany, 2012.

(8) Haider, M.; Uhlemann, S.; Schwan, E.; Rose, H.; Kabius, B.; Urban, K. Electron microscopy image enhanced. Nature 1998, 392, 768-769.

(9) Hansen, P. L.; Wagner, J. B.; Helveg, S.; Rostrup-Nielsen, J. R.; Clausen, B. S.; Topsøe, H. Atom-Resolved Imaging of Dynamic Shape Changes in Supported Copper Nanocrystals. Science 2002, 295, 20532055.

(10) Yoshida, H.; Kuwauchi, Y.; Jinschek, J. R.; Sun, K.; Tanaka, S.; Kohyama, M.; Shimada, S.; Haruta, M.; Takeda, S. Visualizing Gas Molecules Interacting with Supported Nanoparticulate Catalysts at Reaction Conditions. Science 2012, 335, 317-319.

(11) Zheng, H.; Meng, Y. S.; Zhu, Y. Frontiers of in situ electron microscopy. MRS Bull. 2015, 40, 12-18.

(12) Helveg, S.; Lopez-Cartes, C.; Sehested, J.; Hansen, P. L.; Clausen, B. S.; Rostrup-Nielsen, J. R.; Abild-Pedersen, F.; Norskov, J. $\mathrm{K}$. Atomic-scale imaging of carbon nanofibre growth. Nature 2004, 427, 426-429.

(13) Akita, T.; Kohyama, M.; Haruta, M. Electron Microscopy Study of Gold Nanoparticles Deposited on Transition Metal Oxides. Acc. Chem. Res. 2013, 46, 1773-1782.

(14) Zhang, S.; Nguyen, L.; Zhu, Y.; Zhan, S.; Tsung, C.-K.; Tao, F. In-Situ Studies of Nanocatalysis. Acc. Chem. Res. 2013, 46, 1731-1739.

(15) Oh, S. H.; Legros, M.; Kiener, D.; Dehm, G. In situ observation of dislocation nucleation and escape in a submicrometre aluminium single crystal. Nat. Mater. 2009, 8, 95-100.

(16) Legros, M.; Dehm, G.; Arzt, E.; Balk, T. J. Observation of Giant Diffusivity Along Dislocation Cores. Science 2008, 319, 1646-1649.

(17) Jinschek, J. R. Advances in the environmental transmission electron microscope (ETEM) for nanoscale in situ studies of gas-solid interactions. Chem. Commun. 2014, 50, 2696-2706.

(18) Heide, H. G. Electron microscopic observation of specimens under controlled gas pressure. J. Cell Biol. 1962, 13, 147-152.

(19) de Jonge, N.; Ross, F. M. Electron microscopy of specimens in liquid. Nat. Nanotechnol. 2011, 6, 695-704.

(20) Debe, M. K. Electrocatalyst approaches and challenges for automotive fuel cells. Nature 2012, 486, 43-51.

(21) Meier, J. C.; Katsounaros, I.; Galeano, C.; Bongard, H. J.; Topalov, A. A.; Kostka, A.; Karschin, A.; Schuth, F.; Mayrhofer, K. J. J. Stability investigations of electrocatalysts on the nanoscale. Energy Environ. Sci. 2012, 5, 9319-9330.

(22) Quan, Z.; Wang, Y.; Fang, J. High-Index Faceted Noble Metal Nanocrystals. Acc. Chem. Res. 2013, 46, 191-202.

(23) Cui, C.-H.; Yu, S.-H. Engineering Interface and Surface of Noble Metal Nanoparticle Nanotubes toward Enhanced Catalytic Activity for Fuel Cell Applications. Acc. Chem. Res. 2013, 46, 1427-1437.

(24) Porter, N. S.; Wu, H.; Quan, Z.; Fang, J. Shape-Control and Electrocatalytic Activity-Enhancement of Pt-Based Bimetallic Nanocrystals. Acc. Chem. Res. 2013, 46, 1867-1877.

(25) Wang, C.; Chi, M.; Li, D.; Strmcnik, D.; van der Vliet, D.; Wang, G.; Komanicky, V.; Chang, K.-C.; Paulikas, A. P.; Tripkovic, D.; Pearson, J.; More, K. L.; Markovic, N. M.; Stamenkovic, V. R. Design and Synthesis of Bimetallic Electrocatalyst with Multilayered Pt-Skin Surfaces. J. Am. Chem. Soc. 2011, 133, 14396-14403.

(26) Hodnik, N.; Jeyabharathi, C.; Meier, J. C.; Kostka, A.; Phani, K. L.; Recnik, A.; Bele, M.; Hocevar, S.; Gaberscek, M.; Mayrhofer, K. J. J. Effect of ordering of $\mathrm{PtCu} 3$ nanoparticle structure on the activity and stability for the oxygen reduction reaction. Phys. Chem. Chem. Phys. 2014, 16, 13610-13615.
(27) Calle-Vallejo, F.; Tymoczko, J.; Colic, V.; Vu, Q. H.; Pohl, M. D.; Morgenstern, K.; Loffreda, D.; Sautet, P.; Schuhmann, W.; Bandarenka, A. S. Finding optimal surface sites on heterogeneous catalysts by counting nearest neighbors. Science 2015, 350, 185-189.

(28) Jeyabharathi, C.; Hodnik, N.; Baldizzone, C.; Meier, J. C.; Heggen, M.; Phani, K. L. N.; Bele, M.; Zorko, M.; Hocevar, S.; Mayrhofer, K. J. J. Time Evolution of the Stability and Oxygen Reduction Reaction Activity of $\mathrm{PtCu} / \mathrm{C}$ Nanoparticles. ChemCatChem 2013, 5, 2627-2635.

(29) Gan, L.; Heggen, M.; O’Malley, R.; Theobald, B.; Strasser, P. Understanding and Controlling Nanoporosity Formation for Improving the Stability of Bimetallic Fuel Cell Catalysts. Nano Lett. 2013, 13, $1131-1138$.

(30) Snyder, J.; McCue, I.; Livi, K.; Erlebacher, J. Structure/ Processing/Properties Relationships in Nanoporous Nanoparticles As Applied to Catalysis of the Cathodic Oxygen Reduction Reaction. J. Am. Chem. Soc. 2012, 134, 8633-8645.

(31) Gasteiger, H. A.; Kocha, S. S.; Sompalli, B.; Wagner, F. T. Activity benchmarks and requirements for $\mathrm{Pt}$, Pt-alloy, and non-Pt oxygen reduction catalysts for PEMFCs. Appl. Catal., B 2005, 56, 935.

(32) Oezaslan, M.; Heggen, M.; Strasser, P. Size-Dependent Morphology of Dealloyed Bimetallic Catalysts: Linking the Nano to the Macro Scale. J. Am. Chem. Soc. 2012, 134, 514-524.

(33) Wang, D.; Xin, H. L.; Hovden, R.; Wang, H.; Yu, Y.; Muller, D. A.; DiSalvo, F. J.; Abruña, H. D. Structurally ordered intermetallic platinum-cobalt core-shell nanoparticles with enhanced activity and stability as oxygen reduction electrocatalysts. Nat. Mater. 2013, 12, 81-87.

(34) Huang, X.; Zhao, Z.; Cao, L.; Chen, Y.; Zhu, E.; Lin, Z.; Li, M.; Yan, A.; Zettl, A.; Wang, Y. M.; Duan, X.; Mueller, T.; Huang, Y. Highperformance transition metal-doped $\mathrm{Pt} 3 \mathrm{Ni}$ octahedra for oxygen reduction reaction. Science 2015, 348, 1230-1234.

(35) Bele, M.; Jovanovic, P.; Pavlisic, A.; Jozinovic, B.; Zorko, M.; Recnik, A.; Chernyshova, E.; Hocevar, S.; Hodnik, N.; Gaberscek, M. A highly active PtCu3 intermetallic core-shell, multilayered Pt-skin, carbon embedded electrocatalyst produced by a scale-up sol-gel synthesis. Chem. Commun. 2014, 50, 13124-13126.

(36) Han, B.; Carlton, C. E.; Kongkanand, A.; Kukreja, R. S.; Theobald, B. R.; Gan, L.; O’Malley, R.; Strasser, P.; Wagner, F. T.; Shao-Horn, Y. Record activity and stability of dealloyed bimetallic catalysts for proton exchange membrane fuel cells. Energy Environ. Sci. 2015, 8, 258-266.

(37) Ferreira, P. J.; la O', G. J.; Shao-Horn, Y.; Morgan, D.; Makharia, R.; Kocha, S.; Gasteiger, H. A. Instability of Pt/C Electrocatalysts in Proton Exchange Membrane Fuel Cells: A Mechanistic Investigation. J. Electrochem. Soc. 2005, 152, A2256-A2271.

(38) Shao-Horn, Y.; Sheng, W. C.; Chen, S.; Ferreira, P. J.; Holby, E. F.; Morgan, D. Instability of Supported Platinum Nanoparticles in Low-Temperature Fuel Cells. Top. Catal. 2007, 46, 285-305.

(39) Yu, X.; Ye, S. Recent advances in activity and durability enhancement of $\mathrm{Pt} / \mathrm{C}$ catalytic cathode in PEMFC: Part II: Degradation mechanism and durability enhancement of carbon supported platinum catalyst. J. Power Sources 2007, 172, 145-154.

(40) Chen, S.; Gasteiger, H. A.; Hayakawa, K.; Tada, T.; Shao-Horn, Y. Platinum-Alloy Cathode Catalyst Degradation in Proton Exchange Membrane Fuel Cells: Nanometer-Scale Compositional and Morphological Changes. J. Electrochem. Soc. 2010, 157, A82-A97.

(41) Meier, J. C.; Galeano, C.; Katsounaros, I.; Topalov, A. A.; Kostka, A.; Schüth, F.; Mayrhofer, K. J. J. Degradation Mechanisms of $\mathrm{Pt} / \mathrm{C}$ Fuel Cell Catalysts under Simulated Start-Stop Conditions. ACS Catal. 2012, 2, 832-843.

(42) Hodnik, N.; Zorko, M.; Bele, M.; Hočevar, S.; Gaberšček, M. Identical Location Scanning Electron Microscopy: A Case Study of Electrochemical Degradation of PtNi Nanoparticles Using a New Nondestructive Method. J. Phys. Chem. C 2012, 116, 21326-21333.

(43) Mayrhofer, K. J. J.; Meier, J. C.; Ashton, S. J.; Wiberg, G. K. H.; Kraus, F.; Hanzlik, M.; Arenz, M. Fuel cell catalyst degradation on the nanoscale. Electrochem. Commun. 2008, 10, 1144-1147. 
(44) Li, D.; Wang, C.; Strmcnik, D. S.; Tripkovic, D. V.; Sun, X.; Kang, Y.; Chi, M.; Snyder, J. D.; van der Vliet, D.; Tsai, Y.; Stamenkovic, V. R.; Sun, S.; Markovic, N. M. Functional links between Pt single crystal morphology and nanoparticles with different size and shape: the oxygen reduction reaction case. Energy Environ. Sci. 2014, 7, 4061-4069.

(45) Arán-Ais, R. M.; Yu, Y.; Hovden, R.; Solla-Gullón, J.; Herrero, E.; Feliu, J. M.; Abruña, H. D. Identical Location Transmission Electron Microscopy Imaging of Site-Selective Pt Nanocatalysts: Electrochemical Activation and Surface Disordering. J. Am. Chem. Soc. 2015, 137, 14992-14998.

(46) Hodnik, N.; Zorko, M.; Jozinović, B.; Bele, M.; Dražič, G.; Hočevar, S.; Gaberšček, M. Severe accelerated degradation of PEMFC platinum catalyst: A thin film IL-SEM study. Electrochem. Commun. 2013, 30, 75-78.

(47) Hodnik, N.; Jovanovič, P.; Pavlišǐč, A.; Jozinović, B.; Zorko, M.; Bele, M.; Šelih, V. S.; Šala, M.; Hočevar, S.; Gaberšček, M. New Insights into Corrosion of Ruthenium and Ruthenium Oxide Nanoparticles in Acidic Media. J. Phys. Chem. C 2015, 119, 1014010147.

(48) Zadick, A.; Dubau, L.; Sergent, N.; Berthomé, G.; Chatenet, M. Huge Instability of $\mathrm{Pt} / \mathrm{C}$ Catalysts in Alkaline Medium. ACS Catal. 2015, 5, 4819-4824.

(49) Perez-Alonso, F. J.; Elkjær, C. F.; Shim, S. S.; Abrams, B. L.; Stephens, I. E. L.; Chorkendorff, I. Identical locations transmission electron microscopy study of $\mathrm{Pt} / \mathrm{C}$ electrocatalyst degradation during oxygen reduction reaction. J. Power Sources 2011, 196, 6085-6091.

(50) Dubau, L.; Castanheira, L.; Berthomé, G.; Maillard, F. An identical-location transmission electron microscopy study on the degradation of $\mathrm{Pt} / \mathrm{C}$ nanoparticles under oxidizing, reducing and neutral atmosphere. Electrochim. Acta 2013, 110, 273-281.

(51) Arenz, M.; Zana, A. Fuel cell catalyst degradation: Identical location electron microscopy and related methods. Nano Energy 2016, DOI: 10.1016/j.nanoen.2016.04.027.

(52) Yu, Y.; Xin, H. L.; Hovden, R.; Wang, D.; Rus, E. D.; Mundy, J. A.; Muller, D. A.; Abruña, H. D. Three-Dimensional Tracking and Visualization of Hundreds of Pt-Co Fuel Cell Nanocatalysts During Electrochemical Aging. Nano Lett. 2012, 12, 4417-4423.

(53) Baldizzone, C.; Mezzavilla, S.; Carvalho, H. W. P.; Meier, J. C.; Schuppert, A. K.; Heggen, M.; Galeano, C.; Grunwaldt, J.-D.; Schüth, F.; Mayrhofer, K. J. J. Confined-Space Alloying of Nanoparticles for the Synthesis of Efficient PtNi Fuel-Cell Catalysts. Angew. Chem., Int. Ed. 2014, 53, 14250-14254.

(54) Baldizzone, C.; Gan, L.; Hodnik, N.; Keeley, G. P.; Kostka, A.; Heggen, M.; Strasser, P.; Mayrhofer, K. J. J. Stability of Dealloyed Porous Pt/Ni Nanoparticles. ACS Catal. 2015, 5, 5000-5007.

(55) Zorko, M.; Jozinović, B.; Bele, M.; Hodnik, N.; Gaberšček, M. SEM method for direct visual tracking of nanoscale morphological changes of platinum based electrocatalysts on fixed locations upon electrochemical or thermal treatments. Ultramicroscopy 2014, 140, 4450.

(56) Janbroers, S.; Louwen, J. N.; Zandbergen, H. W.; Kooyman, P. J. Insights into the nature of iron-based Fischer-Tropsch catalysts from quasi in situ TEM-EELS and XRD. J. Catal. 2009, 268, 235-242.

(57) Fiordaliso, E. M.; Sharafutdinov, I.; Carvalho, H. W. P.; Grunwaldt, J.-D.; Hansen, T. W.; Chorkendorff, I.; Wagner, J. B.; Damsgaard, C. D. Intermetallic GaPd2 Nanoparticles on $\mathrm{SiO} 2$ for Low-Pressure CO2 Hydrogenation to Methanol: Catalytic Performance and In Situ Characterization. ACS Catal. 2015, 5, 5827-5836.

(58) Malladi, S. R. K.; Tichelaar, F. D.; Xu, Q.; Wu, M. Y.; Terryn, H.; Mol, J. M. C.; Hannour, F.; Zandbergen, H. W. Quasi in situ analytical TEM to investigate electrochemically induced microstructural changes in alloys: AA2024-T3 as an example. Corros. Sci. 2013, 69, 221-225.

(59) Grogan, J. M.; Bau, H. H. The Nanoaquarium: A Platform for In Situ Transmission Electron Microscopy in Liquid Media. J. Microelectromech. Syst. 2010, 19, 885-894.

(60) Ross, F. M. Opportunities and challenges in liquid cell electron microscopy. Science 2015, 350, AAA9886.
(61) Chen, X.; Li, C.; Cao, H. Recent developments of the in situ wet cell technology for transmission electron microscopies. Nanoscale 2015, 7, 4811-4819.

(62) de Jonge, N.; Pfaff, M.; Peckys, D. B. Practical Aspects of Transmission Electron Microscopy in Liquid. Adv. Imaging Electron Phys. 2014, 186, 1-37.

(63) Ross, F. M. In-Situ TEM Studies of Vapor- and Liquid-Phase Crystal Growth. In In-Situ Electron Microscopy; Wiley-VCH Verlag GmbH \& Co. KGaA: Weinheim, Germany, 2012; pp 171-189.

(64) Liao, H.-G.; Zherebetskyy, D.; Xin, H.; Czarnik, C.; Ercius, P.; Elmlund, H.; Pan, M.; Wang, L.-W.; Zheng, H. Facet development during platinum nanocube growth. Science 2014, 345, 916-919.

(65) Yuk, J. M.; Park, J.; Ercius, P.; Kim, K.; Hellebusch, D. J.; Crommie, M. F.; Lee, J. Y.; Zettl, A.; Alivisatos, A. P. High-Resolution EM of Colloidal Nanocrystal Growth Using Graphene Liquid Cells. Science 2012, 336, 61-64.

(66) Schneider, N. M.; Norton, M. M.; Mendel, B. J.; Grogan, J. M.; Ross, F. M.; Bau, H. H. Electron-Water Interactions and Implications for Liquid Cell Electron Microscopy. J. Phys. Chem. C 2014, 118, 22373-22382.

(67) Verch, A.; Pfaff, M.; de Jonge, N. Exceptionally Slow Movement of Gold Nanoparticles at a Solid/Liquid Interface Investigated by Scanning Transmission Electron Microscopy. Langmuir 2015, 31, 6956-6964.

(68) Ngo, T.; Yang, H. Toward Ending the Guessing Game: Study of the Formation of Nanostructures Using In Situ Liquid Transmission Electron Microscopy. J. Phys. Chem. Lett. 2015, 6, 5051-5061.

(69) Evans, J. E.; Jungjohann, K. L.; Browning, N. D.; Arslan, I. Controlled Growth of Nanoparticles from Solution with In Situ Liquid Transmission Electron Microscopy. Nano Lett. 2011, 11, 2809-2813.

(70) Abellan, P.; Woehl, T. J.; Parent, L. R.; Browning, N. D.; Evans, J. E.; Arslan, I. Factors influencing quantitative liquid (scanning) transmission electron microscopy. Chem. Commun. 2014, 50, 48734880.

(71) Grogan, J. M.; Schneider, N. M.; Ross, F. M.; Bau, H. H. Bubble and Pattern Formation in Liquid Induced by an Electron Beam. Nano Lett. 2014, 14, 359-364.

(72) Li, D.; Nielsen, M. H.; Lee, J. R. I.; Frandsen, C.; Banfield, J. F.; De Yoreo, J. J. Direction-Specific Interactions Control Crystal Growth by Oriented Attachment. Science 2012, 336, 1014-1018.

(73) Lewis, E. A.; Haigh, S. J.; Slater, T. J. A.; He, Z.; Kulzick, M. A.; Burke, M. G.; Zaluzec, N. J. Real-time imaging and local elemental analysis of nanostructures in liquids. Chem. Commun. 2014, 50, 10019-10022.

(74) Holtz, M. E.; Yu, Y.; Gunceler, D.; Gao, J.; Sundararaman, R.; Schwarz, K. A.; Arias, T. A.; Abruña, H. D.; Muller, D. A. Nanoscale Imaging of Lithium Ion Distribution During In Situ Operation of Battery Electrode and Electrolyte. Nano Lett. 2014, 14, 1453-1459.

(75) Sutter, E. A.; Sutter, P. W. Determination of Redox Reaction Rates and Orders by In Situ Liquid Cell Electron Microscopy of Pd and Au Solution Growth. J. Am. Chem. Soc. 2014, 136, 16865-16870.

(76) Stevens, A.; Yang, H.; Carin, L.; Arslan, I.; Browning, N. D. The potential for Bayesian compressive sensing to significantly reduce electron dose in high-resolution STEM images. Microscopy 2014, 63, $41-51$.

(77) Williamson, M. J.; Tromp, R. M.; Vereecken, P. M.; Hull, R.; Ross, F. M. Dynamic microscopy of nanoscale cluster growth at the solid-liquid interface. Nat. Mater. 2003, 2, 532-536.

(78) Radisic, A.; Vereecken, P. M.; Hannon, J. B.; Searson, P. C.; Ross, F. M. Quantifying Electrochemical Nucleation and Growth of Nanoscale Clusters Using Real-Time Kinetic Data. Nano Lett. 2006, 6, $238-242$.

(79) White, E. R.; Singer, S. B.; Augustyn, V.; Hubbard, W. A.; Mecklenburg, M.; Dunn, B.; Regan, B. C. In Situ Transmission Electron Microscopy of Lead Dendrites and Lead Ions in Aqueous Solution. ACS Nano 2012, 6, 6308-6317.

(80) Chen, X.; Noh, K. W.; Wen, J. G.; Dillon, S. J. In situ electrochemical wet cell transmission electron microscopy character- 
ization of solid-liquid interactions between $\mathrm{Ni}$ and aqueous $\mathrm{NiCl}$. Acta Mater. 2012, 60, 192-198.

(81) Chee, S. W.; Pratt, S. H.; Hattar, K.; Duquette, D.; Ross, F. M.; Hull, R. Studying localized corrosion using liquid cell transmission electron microscopy. Chem. Commun. 2015, 51, 168-171.

(82) Zhu, G.-Z.; Prabhudev, S.; Yang, J.; Gabardo, C. M.; Botton, G. A.; Soleymani, L. In Situ Liquid Cell TEM Study of Morphological Evolution and Degradation of Pt-Fe Nanocatalysts During Potential Cycling. J. Phys. Chem. C 2014, 118, 22111-22119.

(83) https://www.hydrogen.energy.gov/pdfs/review14/fc020_ more_2014_o.pdf.

(84) Toyota, JFCC breakthrough in real-time observation of fuel cell catalyst degradation. Fuel Cells Bull.. 2015, 2015, 14-15.10.1016/ S1464-2859(15)30167-X

(85) Wu, F.; Yao, N. Advances in sealed liquid cells for in-situ TEM electrochemial investigation of lithium-ion battery. Nano Energy 2015, 11, 196-210.

(86) Gu, M.; Parent, L. R.; Mehdi, B. L.; Unocic, R. R.; McDowell, M. T.; Sacci, R. L.; Xu, W.; Connell, J. G.; Xu, P.; Abellan, P.; Chen, X.; Zhang, Y.; Perea, D. E.; Evans, J. E.; Lauhon, L. J.; Zhang, J.-G.; Liu, J.; Browning, N. D.; Cui, Y.; Arslan, I.; Wang, C.-M. Demonstration of an Electrochemical Liquid Cell for Operando Transmission Electron Microscopy Observation of the Lithiation/ Delithiation Behavior of Si Nanowire Battery Anodes. Nano Lett. 2013, 13, 6106-6112.

(87) Mehdi, B. L.; Qian, J.; Nasybulin, E.; Park, C.; Welch, D. A.; Faller, R.; Mehta, H.; Henderson, W. A.; Xu, W.; Wang, C. M.; Evans, J. E.; Liu, J.; Zhang, J. G.; Mueller, K. T.; Browning, N. D. Observation and Quantification of Nanoscale Processes in Lithium Batteries by Operando Electrochemical (S)TEM. Nano Lett. 2015, 15, 2168-2173.

(88) Unocic, R. R.; Sun, X.-G.; Sacci, R. L.; Adamczyk, L. A.; Alsem, D. H.; Dai, S.; Dudney, N. J.; More, K. L. Direct Visualization of Solid Electrolyte Interphase Formation in Lithium-Ion Batteries with In Situ Electrochemical Transmission Electron Microscopy. Microsc. Microanal. 2014, 20, 1029-1037.

(89) Noh, K. W.; Dillon, S. J. Morphological changes in and around $\mathrm{Sn}$ electrodes during $\mathrm{Li}$ ion cycling characterized by in situ environmental TEM. Scr. Mater. 2013, 69, 658-661.

(90) Liu, Y.; Dillon, S. J. In situ observation of electrolytic H2 evolution adjacent to gold cathodes. Chem. Commun. 2014, 50, 17611763.

(91) Noh, K. W.; Tai, K.; Mao, S.; Dillon, S. J. Grain Boundary Parting Limit during Dealloying. Adv. Eng. Mater. 2015, 17, 157-161.

(92) Unocic, R. R.; Sacci, R. L.; Brown, G. M.; Veith, G. M.; Dudney, N. J.; More, K. L.; Walden, F. S. I.; Gardiner, D. S.; Damiano, J.; Nackashi, D. P. Quantitative Electrochemical Measurements Using In Situ ec-S/TEM Devices. Microsc. Microanal. 2014, 20, 452-461.

(93) Cherevko, S.; Zeradjanin, A. R.; Topalov, A. A.; Kulyk, N.; Katsounaros, I.; Mayrhofer, K. J. J. Dissolution of Noble Metals during Oxygen Evolution in Acidic Media. ChemCatChem 2014, 6, 22192223. 